could have conceivably drawn together all the diverse contents is the contrast between a 'patchy' view of the phenomenon in question, and an older view of the same phenomenon in which spatial structure was ignored. Surprisingly though, not all the authors explicitly address the question of why spatial structure is important. (Or, why wholes are not just the sums of their patches.)

The book is a patchwork of interesting and in some cases excellent chapters, which nonetheless adds up to little more than the equivalent of several journal

\section{Cache and carry}

\section{Hans Kruuk}

Food Hoarding in Animals. By Stephen B. Vander Wall. University of Chicago Press: 1990. Pp. 445. Hbk \$87.50; £60.75, Pbk $\$ 34.50 ; £ 23.95$.

A LARGE majority of animal species are, in one way or other, food limited. Little surprise, then, that mechanisms have evolved for them to have some control over the availability of food resources to themselves or their kin. Most commonly, such control of access takes the form of territoriality, where feeding territories are defended against exploitation by conspecifics, enabling exploitation at optimal efficiency by territory 'owners'. An alternative, or complementary, method of controlling the vagaries of food availability is caching or storing at times of plenty. Widely practiced throughout the animal kingdom, food hoarding has important implications in ecology.

Even in its simplest form, hoarding is a highly complicated phenomenon; articles by each of the contributors. It provides a convenient, if highly selective, introduction to current issues, but is far from a comprehensive work of reference. Population and community ecology seem ready for a bolder synthesis of recent work on spatial dynamics, better integrated if perhaps also more narrowly focused than this book.

Susan Harrison is in the Interdisciplinary Research Centre in Population Biology, Imperial College at Silwood Park, Ascot, Berkshire SL5 7PY, UK.

watching it, one is assaulted by a range of questions about its exact mechanism, the neural processes involved, survival value in ecological terms, evolution, the problems involved in recovery of the caches, the effects of fruit hoarding on plant dispersion, and so on. Vander Wall in Food Hoarding in Animals deals with all of these, ably reviewing the evidence from about 1,500 references dealing with vertebrates, invertebrates, and with the plants of which the dispersal depends on animal food storing. The book is a tour de force which will be of great value to students of many disciplines.

Vander Wall himself has experimented on some spectacular examples of food caching in birds, among others in nutcrackers and jays. Much of his research, like that of others, centres on the recovery of caches, the spatial memory of the birds, and the kinds of environmental clues used. Despite ingenious experiments and fascinating laboratory results, one is still a long way from understanding how nutcrackers manage to recover such a large proportion of the seeds which they stored several months earlier, when storage took place under the colourful branches of

\section{IMAGE UNAVAILABLE FOR COPYRIGHT REASONS}

Saving it for later - the jay (Garrulus glandarius) caches surplus fruit and nuts. What makes some species cache whereas others do not?

\section{New in paperback}

- The Ubiquity of Chaos edited by Saul Klassner is published by the American Association for the Advancement of Science and draws together contributors in fields as disparate as physiology and quantum mechanics in which nonlinear dynamics act, price $\$ 31,50$.

- Cytokines by Anthony Meager aims to provide a comprehensive and up-to-date introduction to the biology of this diverse group of secreted proteinaceous molecules. Published by Open University Press, price £15.99. (Hardback price £35.)

- Cambridge University Press have just released the second edition of Mass Spectroscopy edited by H. E. Duckworth, R. C. Farber and the late $V$. S. Venkatasubramanian. The book is intended for students and for university and industrially based scientists and describes the principles of mass spectroscopy and its uses. Price $£ 17.50, \$ 29.95$.

- In Plasma Dynamics published Oxford University Press, R. O. Dendy explains the fundamental concepts of plasma physics, price $£ 12.50$ (Also available in hardback, price $£ 27.50$.)

- New from Gordon and Breach is Reversing the Arms Race: How to Achieve and Verify Deep Reductions in the Nuclear Arsenals edited by Frank von Hippel and Roald Sagdeev, price $\$ 24$. (Also available in hardback, price $\$ 49$.)

- Evolutionary Stability: Logical and Material Aspects of a Unified Theory of Biosocial Evolution by Gebhard Geiger offers approaches for the solution of problems raised by the recent sociobiology debate. Published by Springer, price DM 79.

trees in autumn, and recovery from under a metre of snow in winter.

Vander Wall discusses in detail the conditions under which caching could evolve, and goes some way to explain why some species do and others do not. The main argument is that some just do not have the raw material, "some genetically controlled trait from which natural selection could produce the advantageous characteristic". Dangerous ground, this; clearly, caching has evolved many times independently in different species, and over a huge period in evolutionary history. The fact that all canids cache food in exactly the same, unique manner suggests a very old trait in that family, whereas several quite different ways of hoarding food among hyaenids or felids indicate that there are many more recent arrivals of caching on the scene of evolution. It means that it is worthwhile looking for the selective advantages of not hoarding. This is what I would do if I had to explain why a crow beautifully caches his surplus chunk of carrion, whereas a herring gull in exactly the same conditions does not. This book inspires one to think this way; apart from providing an excellent review, it also stimulates by identifying many open questions.

Hans Kruuk is in the Institute of Terrestrial Ecology, Glassel, Banchory, Kincardineshire AB31 4BY, UK. 